\title{
Soil carbon and nitrogen dynamics in a tropical peatland
}

\begin{abstract}
The conversion of peat swamp forest to oil palm cultivation has resulted in the loss of stored nutrients in the peat soil, especially to the atmosphere. Soil carbon and nitrogen are the two major nutrients that are found in large quantities in the peat soil. Therefore this chapter studies the dynamics of these two primary nutrients within the peatland and how their losses are influenced by seasonal changes. Detailed samplings were carried out in wet and dry periods, with samples collected at three different depths during the dry and wet seasons. The flash combustion method using the LECO analyzer was part of the analysis of carbon and nitrogen. The results of the analyses of the soil carbon obtained in triplicates showed that the soil carbon at the peat surface is higher than that below the surface. The soil carbon recorded at the surface (0.5. $\mathrm{m}$ ) during the wet season was $47.29 \%$, which is higher than that recorded at the surface during the dry period. $1.34 \%$ of the soil nitrogen was observed at the surface during the wet period compared to $1.2 \%$ recorded during the dry spell. Rainfall was considered to be the main driver of both soil carbon and nitrogen in the tropical peatland, coupled with the fact that more nutrients were observed at the soil surface due to microbial activities at the surface. Hence, sustaining tropical peatlands would mean that practices that encourage nutrient loss from the peatlands to be controlled and well managed so as not to aggravate the climate change process that is associated with the nutrients' loss to the atmosphere.
\end{abstract}

Keyword: Soil carbon; Soil nitrogen; Peat swamp forests; Tropical peatland; Climate change 